\title{
Medicine in Mind, Healing at Heart: Big Data and Its Limits in Compassionate Care
}

\author{
John W. Davis, BA (MD PhD Student)
}

In 2020, as a 24-year-old MD PhD student studying cardiovascular population health, I suffered a nonST elevated myocardial infarction while playing basketball. It was confirmed the cause was familial hypercholesterolemia leading to $95 \%$ + occlusions of both the left anterior descending and left circumflex arteries. The following reflective essay describes my experience as a patient grappling with his own mortality and how those experiences have shaped how I now view my purpose as a future physician. The purpose of this essay is to encourage all physicians and physicians in training to practice reflection and to allow themselves to fully experience the pain and suffering of the patients for whom they care, even amidst times of personal uncertainty. ( $\mathrm{J}$ Am Board Fam Med 2021;34:449-451.)

Keywords: Death, Humanities, Medical Ethics, Medicine, Narrative Medicine

By 24 years old, I had decided that death was quite evitable for me. This, of course, was more willful ignorance than conscious decision. As an MD PhD student halfway through my education, studying cardiovascular disease through population health, I had done what so many health care providers have done. I had begun to see death and disease as a thing to be studied, rather than an experience to be felt and grappled with. This change became glaringly apparent to me once I suffered from illness myself: I dropped from a heart attack in the middle of my second year of medical school.

I first learned about my diagnosis-familial hypercholesterolemia $(\mathrm{FH})$, type II-during my junior year of high school. On a routine lipid panel, it was found that my serum low-density lipoprotein was $411 \mathrm{mg} / \mathrm{dL}$. Because I grew up without any medical background, this meant very little to me. I was told that I might need to take a statin, and it would become more important as I got older. For the most part, I focused on the "once I was older" bit and only took the drug in spurts. I have never experienced any

This article was externally peer reviewed.

Submitted 1 July 2020; revised 18 September 2020; accepted 4 October 2020.

From the University of Texas-Medical Branch at Galveston.

Funding: None.

Conflicts of interest: None.

Corresponding author: John W. Davis, BA, University of Texas Medical Branch, Galveston, TX 77555 (E-mail: jowdavis@utmb.edu). obvious side effects, but taking a statin has never made me "feel better." It was easy to forget it.

The decision to become a cardiovascular MD $\mathrm{PhD}$ student—studying statins, no less-was more kismet than intention. During a readings course, I remember being fascinated about an apparent "nocebo effect" detected by the Anglo-Scandinavian Cardiac Outcomes Trial trialists. ${ }^{1}$ On the suggestion of my faculty mentors, I chose to begin exploring statin literature. The choice felt quite impersonal. As I became more familiar with the statin literature, though, I also became more familiar with a glaring undertone in statin therapy: some clinicians and patients alike have become insistent that statin therapy is quite sinister, as discussed in a recent study. ${ }^{2}$ From reports of serious myopathy to underlying, small increases in hemorrhagic stroke and diabetes incidence, ${ }^{3}$ there has been a growing controversy over the utility of statins over the last decade in light of other risks. ${ }^{3}$

Despite an abundance of evidence on the benefits of statin therapy-enormous reductions in risk for cardiovascular events-I could not help but focus on the side effects. I was just 24-what if I developed diabetes or had a debilitating stroke from taking a statin for the next 50 years? I felt no different when I took the statin but certainly began to worry about the side effects. I had seen plenty of diabetes and strokes in the clinic, and I saw the immense suffering they bring. That terrified me far more than a theoretical heart attack 15 years from 
now. I allowed this information to implicitly bias my perceptions on statins, and I went from taking it regularly to rarely, and then to never at all.

February 2020, all that changed. I had continued to exercise since college but had progressively felt worse throughout medical school. It was not clear to me (or my doctors) what was happening: for over a year, I had palpitations, horrible abdominal pain after meals, and just felt "off” otherwise. I felt faint when I exercised, which I brushed off as "letting myself go" while I studied for Step 1. In a flash, it became far too apparent that something was seriously wrong. Just 2 or 3 minutes after joining a pickup basketball game at our hospital's gym, I felt weak, dizzy, and then a searing pain between my shoulder blades as my vision faded and my ears started to ring. I began to panic, feeling completely out of control. I had a nagging cough and felt "off" for a few days beforehand-Maybe it was pericarditis? The troponins continued to climb, squashing any hope I had of an easy fix. I called my wife and asked her to join me. I felt weak, and lost - there was nothing I could do.

Late that night, the medical team informed me I was being treated as a non-ST elevated myocardial infarction (NSTEMI) case. For the first time, I considered what this might mean. What is going to bappen to me? I asked myself. What does this mean for my wife and family? Have I doomed my 23-year-old bride to be a widow? As a population health researcher studying large datasets of cardiovascular disease data, I felt I had a pretty good handle on what my risk was. The Centers for Disease Control and Prevention provides numerous frequency tables on mortality for people of all ages, races, and walks of life, and I was aware that any given person might die on any given day. Frequencies and likelihood meant nothing to me while I lay there, contemplating if my wife and I would reach our second wedding anniversary together. I felt incredibly ashamed that I had failed to seize what control I had over my health.

And yet, frequencies and likelihoods were all I knew. Despite the lorazepam I requested to keep my anxiety from overwhelming me, I stayed up that night researching 30-day, 90-day, and 5-year mortality rates for those suffering NSTEMIs. Wrong cohort, I thought to myself as I studied a meta-analysis of 55-year-olds to 80-year-olds who had undergone percutaneous coronary intervention. Too much uncertainty, I said to myself as I researched reincidence of MIs in patients with FH. How were these big data studies going to prove to me that I would be okay? As I lay on the table watching my left anterior descending and left circumflex arteries be revascularized, I began to weep for the first time in years. I felt perhaps even more humiliated that what was killing me was atherosclerosis, a disease I had intensely studied for years.

The most obvious lesson, perhaps, is that I really should have been taking my statin. In the general population, 11 people in 1000 taking a statin for 5 years will not suffer a major vascular event because of their statin. ${ }^{4}$ I have immense regret that, for all my knowledge and education, I allowed barely significant findings to dissuade me from taking a medicine that may one day save my life.

Perhaps much more important, though, is my realization that so many others now have the same fear and uncertainty that I did about taking their statin. And frankly, the memories of those I serve who have suffered from diabetes and strokes were far more persuasive than the cold, hard facts I try to provide through my own investigations. I knew the exact 5year relative risk reduction on major vascular events by high-intensity statin therapy, and it never mattered to me until I experienced a major vascular event. Thus, for all the good brought about by big data and good medical education, I found them to be worthless in convincing myself of the importance to take a statin.

I cannot make my future patients experience a major vascular event to convince them of the importance of statin therapy, nor would any reasonable person wish to do so. And, of course, it is important to know the evidence and relative benefits and risk of a therapy for our patients. However, I am incredibly grateful that I now have a far more powerful tool at my disposal in communicating about statins: lived experience. I cannot expect to persuade my patients to take a medicine by "having all the answer"-there is no amount of statistical knowledge that would have resulted in me taking my statin each day before I had my heart attack. Big data and relative risks are abstract concepts.

Today, I run nearly 20 miles per week, savor every moment I can with my wife and loved ones, and relentlessly strive to be a companion to the patients I serve. Who knows if I might have suffered another event, had I chosen not to religiously take my statin since that day. The risk of a stroke or diabetes still scares me, but I have taken control of my health the best I can with a medley of diet, exercise, and medical therapy. Medical education and big data may put medicine in mind, but I must keep healing at heart 
with stories and personal narratives to best serve my patients.

I would like to thank Dr. Lauren Barron and the Medical Humanities Department at Baylor University. The title of this essay and the reflections within were inspired by my time working with Dr. Lauren Barron and her Medical Humanities Department.

To see this article online, please go to: http://jabfm.org/content/ 34/2/449. full.

\section{References}

1. Gupta A, Thompson D, Whitehouse A, et al. Adverse events associated with unblinded, but not with blinded, statin therapy in the Anglo-Scandinavian Cardiac Outcomes Trial-Lipid-Lowering Arm (ASCOT-
LLA): a randomised double-blind placebo-controlled trial and its non-randomised non-blind extension phase. Lancet 2017;389:2473-81.

2. Golder S, O'Connor K, Hennessy S, Gross R, Gonzalez-Hernandez G. Assessment of beliefs and attitudes about statins posted on Twitter: a qualitative study. JAMA Netw Open 2020;3: e208953.

3. Collins R, Reith C, Emberson J, et al. Interpretation of the evidence for the efficacy and safety of statin therapy. Lancet 2016;388:2532-61.

4. Cholesterol Treatment Trialists' Collaborators. The effects of lowering LDL cholesterol with statin therapy in people at low risk of vascular disease: metaanalysis of individual data from 27 randomised trials. Lancet 2012;380:581-90. 